\title{
Comparative Analysis of American Academy of Pediatrics and European Society of Hypertension Guidelines for the Diagnosis and Treatment of Pediatric Hypertension
}

\author{
Se Jin Park, M.D., Ph.D. ${ }^{1}$ \\ Jae II Shin, M.D., Ph.D. ${ }^{2}$ \\ 'Department of Pediatrics, Daejeon \\ Eulji Medical Center, Eulji University \\ School of Medicine, Daejeon, Republic \\ of Korea, ${ }^{2}$ Department of Pediatrics, \\ Severance Children's Hospital, Yonsei \\ University College of Medicine, Seoul, \\ Republic of Korea
}

\section{Corresponding author:}

Jaell Shin, M.D., Ph.D.

Department of Pediatrics, Severance

Children's Hospital, Yonsei University

College of Medicine, Seoul 03722,

Republic of Korea

Tel: $+82-2-2228-2050$

Fax: +82-2-393-9118

E-mail:shinji@yuhs.ac

Received: 12 December 2021

Revised: 19 December 2021

Accepted: 24 December 2021
This is an open-access article distributed under the terms of the Creative Commons Attribution Non-Commercial License (http:// creativecommons.org/licenses/by-nc/4.0/) which permits unrestricted non-commercial use, distribution, and reproduction in any medium, provided the original work is properly cited.

Copyright (C) 2021 The Korean Society of Pediatric Nephrology
Childhood hypertension (HTN) has become a significant public health issue because of the increased risk of cardiovascular disease in adulthood. However, childhood HTN is underrecognized and underdiagnosed in clinical practice. The European Society of Hypertension in 2016 and the American Academy of Pediatrics (AAP) in 2017 published updated guidelines for the screening, prevention, and management of pediatric HTN. There were notable differences between the two guidelines as well as many similarities. The updated AAP guidelines have clarified and simplified the recommendations for screening, diagnosis, and treatment of childhood HTN based on current evidence. This review highlights the important developments in both guidelines, focusing on recent advances in the classification and treatment of childhood HTN.

Key words: Blood pressure, Child, Guideline, Hypertension

\section{Introduction}

Since the "Fourth Report on the Diagnosis, Evaluation, and Treatment of High Blood Pressure in Children and Adolescents" (2004 Fourth Report) was published in 2004, interest in childhood hypertension (HTN) has increased $^{1)}$. Increased blood pressure (BP) in children and adolescents increases the risk of cardiovascular disease (CVD) in adulthood, which is known as the tracking phenomenon ${ }^{2)}$. Mounting evidence has also shown that childhood and adolescent HTN increase the risk of adult cardiovascular morbidity and mortality ${ }^{3,4}$. The global rise in childhood HTN is likely associated with the growing prevalence of children who are overweight and obese ${ }^{5}$.

In an effort to delay the present trajectory, new studies related to childhood HTN have been conducted, and two updated clinical practice guidelines for the management of $\mathrm{BP}$ in children and adolescents have recently been published. In 2016, the European Society of Hypertension (ESH) updated the 2009 guidelines and published new guidelines (2016 the European Society of Hypertension guidelines [2016 ESHG]) to increase efforts toward prevention and management of HTN in the pediatric age, thus also helping relieve the burden of CVD in adults ${ }^{6}$. In 2017, the American Academy of Pediatrics Clinical Practice Guideline (AAP CPG) for Screening and Management of 
High Blood Pressure in Children and Adolescents (2017 AAP CPG) was published to update the current guidelines based on a systematic review of evidence published since the 2004 Fourth Report ${ }^{7}$. The aim of the 2017 AAP CPG was not only to provide an update on topics relevant to the diagnosis, evaluation, and management of pediatric HTN, but also to improve early recognition of pediatric HTN by simplifying the diagnosis and evaluation of HTN in children and adolescents. The 2017 AAP CPG includes 30 key action statements and 27 additional recommendations (Appendix 1 in the 2017 AAP CPG).

Both guidelines produced significant reactions and were discussed in the HTN community. Although there are many similarities between these two guidelines, there are also several notable differences. These differences suggest that further studies are needed to prevent and treat HTN in childhood and to improve adult CVD. The goal of this review is to highlight new guidelines for the diagnosis and management of pediatric HTN.

\section{Definition and classification of HTN}

Both the 2016 ESHG and 2017 AAP CPG regard a BP value $<90$ th percentile by age, sex, and height as normal $\mathrm{BP}^{6,7)}$. HTN is defined in children aged $<13$ years in the 2017 AAP CPG and $<16$ years in the 2016 ESHG as a persistent elevation in BP measured clinically at or $\geq 95$ th percentile on at least three separate occasions ${ }^{6,7)}$.
According to the 2016 ESHG, children with an average systolic BP (SBP) and/or diastolic BP (DBP) between the 90th and 95th percentile are classified as having highnormal $\mathrm{BP}^{6}$. The diagnostic criteria for elevated $\mathrm{BP}$ in children depend on the fact that BP in children increases with age and body size. Therefore, it is inappropriate to use a single BP level to define HTN, as is done in adults. For adolescents aged $\geq 16$ years, the same single, static thresholds $(\geq 140 / 90 \mathrm{mmHg}$ ) defining BP categories used in adults were adopted, allowing a gentle transition from pediatric to adult providers ${ }^{6}$. This is quite different from the Fourth Report that used percentiles to define the BP category for adolescents, while maintaining the Fourth Report criteria in young people $<16$ years of age.

However, in 2017, the term "elevated BP" was used to replace "prehypertension" ${ }^{\text {7,8) }}$. New thresholds for elevated BP, stage $1 \mathrm{HTN}$, and stage $2 \mathrm{HTN}$ were also provided for adolescents aged $\geq 13$ years ${ }^{7,8)}$. The term "high-normal BP" in 2016 ESHG was converted to "elevated BP" in the 2017 AAP CPG. The new BP cutoff values for screening and diagnosing pediatric HTN, proposed by the 2017 AAP $\mathrm{CPG}$, differ from those by the ESHG ${ }^{7}$. The cutoffs of SBP and DBP were lowered, whereas a single cutoff of 130/80 $\mathrm{mmHg}$ and $140 / 90 \mathrm{mmHg}$ was recommended to define stage 1 and stage $2 \mathrm{HTN}$, respectively, in adolescents aged $\geq 13$ years (Table 1). This decision has provoked a large debate not only for the adults' criteria, as the ESH was determined to maintain the cutoff of $140 / 90 \mathrm{mmHg}$, but also for the pediatric criteria, as the ESHG has not been renewed

Table 1. Diagnostic Criteria in Pediatric Hypertension

\begin{tabular}{|c|c|c|}
\hline 2017 AAP CPG & & 2016 ESHG \\
\hline $1-13$ years & Children & $0-15$ years \\
\hline$<90$ th $p$ & Normal BP & $<90$ th $p$ \\
\hline$\geq 90$ th $p$ to $<95$ th $p$ or $120 / 80$ (whichever is lower) & $\begin{array}{c}\text { Elevated BP } \\
\text { (High-normal BP) }\end{array}$ & $\geq 90$ th $p$ to $<95$ th $p$ \\
\hline $\begin{array}{l}\geq 95 \text { th } p \text { to }<95 \text { th } p+12 \mathrm{mmHg} \text { or } 130 / 80 \text { to } 139 / 89 \mathrm{mmHg} \\
\text { (whichever is lower) }\end{array}$ & Stage 1 HTN & 95th $p$ to 99th $p+5 \mathrm{mmHg}$ (ISH: SBP $\geq 95$ th $p \&$ DBP $<90$ th $p$ ) \\
\hline$\geq 95$ th $p+12 \mathrm{mmHg}$ or $\geq 140 / 90 \mathrm{mmHg}$ (whichever is lower) & Stage 2 HTN & $>99$ th $p+5 \mathrm{mmHg}$ \\
\hline$\geq 13$ years & Adolescents & $\geq 16$ years \\
\hline$<120 /<80 \mathrm{mmHg}$ & Normal BP & $<130 / 85 \mathrm{mmHg}$ \\
\hline $120 /<80$ to $129 /<80 \mathrm{mmHg}$ & $\begin{array}{c}\text { Elevated BP } \\
\text { (High-normal BP) }\end{array}$ & $130-139 / 85-89 \mathrm{mmHg}$ \\
\hline $130 / 80$ to $139 / 89 \mathrm{mmHg}$ & Stage 1 HTN & 140-159/90-99 mmHg (ISH: $\geq 140 /<90$ mmHg) \\
\hline$\geq 140 / 90 \mathrm{mmHg}$ & Stage 2 HTN & $160-179 / 100-109 \mathrm{mmHg}$ \\
\hline
\end{tabular}

Abbreviations: AAP CPG, American Academy of Pediatrics Clinical Practice Guideline; ESHG, European Society of Hypertension Guideline; BP, blood pressure; HTN, hypertension; ISH, isolated systolic hypertension; SBP, systolic blood pressure; DBP, diastolic blood pressure; p, percentile. 
yet $^{9}$. The difference in the definition of HTN in children and adolescents may cause confusion and contrasting results in both epidemiological research and clinical practice.

In the previous guidelines from 2004, children who are overweight and obese were included. In 2017, the AAP CPG renewed the normative tables for pediatric $\mathrm{BP}$ values by excluding overweight and obese children who had a body mass index (BMI) $\geq 85$ th percentile ${ }^{10,11)}$. This resulted in a decrease of 2-3 mmHg in BP values compared to those in the 2004 Fourth Report. Stage 2 HTN for children $<13$ years was defined as BP values $\geq 95$ th percentile +12 $\mathrm{mmHg}$ (or $\geq 140 / 90 \mathrm{mmHg}$ ) instead of the 99th percentile+ $5 \mathrm{mmHg}$ (Table 1). The 2017 AAP CPG applied an adult threshold of 130/80 $\mathrm{mmHg}$ to adolescents, both male and female, aged $\geq 13$ years ${ }^{10)}$. The absolute BP cutoff points were introduced to follow the updated adult HTN guidelines and to simplify the process of identifying and classifying HTN in adolescents ${ }^{12)}$. In particular, in view of Korean pediatricians, the new percentile tables are easy to use at office, as height values were added to the table in centimeters, which are used as the unit ${ }^{7}$. In addition to applying a static threshold to adolescents, the 2017 AAP CPG has a new simplified screening table with BP cutoffs based on the 90th percentile $\mathrm{BP}$ at the 5th percentile of height for every age for males and females $<13$ years of age ${ }^{7}$. The goal of this table is not to diagnose elevated BP or HTN by itself but to identify children and adolescents who need further evaluation of their BP with repeat BP measurements.

Recent evidence revealed that the use of the 2017 AAP CPG identified a higher proportion of hypertensive young people with abnormal cardiometabolic risk ${ }^{13)}$ or target organ damage $(\mathrm{TOD})^{14)}$, resulting in an overall increase in the prevalence of $\mathrm{HTN}^{8,15,16)}$. The simplified screening table in the 2017 AAP CPG better contributes to recognizing and classifying those with obesity and other CVD risk factors as hypertensive when compared to the 2016 ESHG. According to the screening table, children who have increased $B P$ should be evaluated using the extended percentile table or a cutoff BP value of 120/80 $\mathrm{mmHg}$ should be used for children aged $\geq 13$ years ${ }^{7)}$.

\section{Treatment strategies}

\section{Target blood pressure values}

The main goals of treatment for both primary and secondary HTN are to reduce the risk of TOD in childhood and decrease the risk of HTN and CVD in adulthood. The 2017 AAP CPG recommends that the treatment goal of non-pharmacologic and pharmacologic therapy is to reduce SBP and DBP to $<90$ th percentile and $<130 / 80 \mathrm{mmHg}$ in adolescents $\geq 13$ years old ${ }^{7}$. The mean arterial pressure should be maintained $<50$ th percentile in children with chronic kidney disease $(\mathrm{CKD})^{7)}$.

In the 2016 ESHG, a BP <95th percentile for age, sex, and height is recommended for the general hypertensive population. However, if the goal can be accomplished by well-tolerated treatment, a BP $<90$ th percentile should be considered $^{6}$. For children with CKD, strict BP control leads to better long-term renal survival ${ }^{17)}$. A BP goal of $<50$ th percentile is recommended in children with proteinuric $\mathrm{CKD}$, as proteinuria is an important modifier of the renoprotective effect of intensified BP control ${ }^{6}$. In patients aged $\geq 16$ years, the cutoff values for office BP were $130 / 80 \mathrm{mmHg}$ or $125 / 75 \mathrm{mmHg}$ with proteinuric $\mathrm{CKD}^{6}$.

Children with type 1 or 2 diabetes mellitus (DM) are considered to have increased long-term risk for HTN and renal damage ${ }^{18,19)}$. Therefore, it is appropriate for target BP values to be $<75$ th percentile in children with non-proteinuric $\mathrm{CKD}$ and $<50$ th percentile in children with proteinuric $\mathrm{CKD}^{6}$.

\section{Lifestyle interventions}

Both the 2017 AAP CPG and the 2016 ESHG initially recommended lifestyle modifications to control BP. Particularly, in overweight and obese children, it has been demonstrated that lifestyle modifications such as a healthy diet, exercise, and behavioral therapy lead to improvements in both weight reduction and $\mathrm{BP}$ control ${ }^{20)}$. The $2017 \mathrm{AAP}$ CPG seems to emphasize the Dietary Approach to Stop Hypertension (DASH)-type diet, which consists of a high daily intake of fruits and vegetables, low-fat milk products, and whole grains, and a low intake of added sugar and sweets (including sweetened beverages) and dietary sodium. A reduction in salt ( $<3 \mathrm{~g}$ per day) decreases SBP and DBP by 1.2 and $1.3 \mathrm{mmHg}$, respectively (Table 2$)^{6}$. 
Moderate to vigorous exercise at least 3 to 5 days per week (30-60 minutes per session) helps to reduce $\mathrm{BP}^{6,7)}$. Of note, the 2016 ESHG recommends that BMI should be maintained at $<85$ th percentile to prevent becoming overweight ${ }^{6}$. Children with a BMI $>95$ th percentile require gradual weight loss (1-2 kg/month) to achieve a value $<85$ th percen tile.

\section{Pharmacologic treatment}

Despite lifestyle modifications, children who remain hypertensive or who have symptomatic HTN, stage $2 \mathrm{HTN}$ without modifiable risk factors (e.g., obesity), or any stage of HTN associated with CKD or DM therapy should be initiated with pharmacologic treatment ${ }^{7)}$. An individual approach can be made in children with high-normal BP if hypertensive TOD is already present ${ }^{6}$.

It is logical to initiate monotherapy that can be administered once a day due to the benefits of simplicity and adherence to administration. After treatment with the lowest dose, BP should be measured at 2-4-week intervals. If the target BP goal is not achieved, the dose should be increased. Adverse effects should also be monitored during dose increments.

There are eight classes of antihypertensive drugs that may potentially be first-line agents, including angiotensin-converting enzyme inhibitors (ACEi), angiotensin receptor blockers (ARBs), beta-blockers, calcium channel blockers (CCBs), and diuretics ${ }^{6}$. Drug choice should be targeted to the child's underlying pathophysiology and the presence of concurrent disorders ${ }^{6}$. Although there are limited evidence and trials related to antihypertensives used in childhood, and their adverse effects and long-term cardiovascular outcomes, the use of ACEi and ARBs are recommended as first-line agents in populations with obesityassociated primary $\mathrm{HTN}^{21)}$. CCBs are a reasonable alternative in the absence of treatment effects with ACEi and ARBs, whereas beta-blockers are avoided in terms of safety in children without vasodilatory capacity and thiazide diuretics $^{22)}$. In children with CKD and $\mathrm{HTN}$, proteinuria, or DM, an ACEi or ARB is also recommended as the initial antihypertensive agent, unless there is an absolute contraindication such as pregnancy in adolescence ${ }^{7)}$.

The use of combination therapy is recommended if a single agent does not successfully achieve target $\mathrm{BP}^{6)}$. The second drug to be chosen is diuretics because antihypertensive agents can generally cause water and salt retention. Increased consumption of vegetables and fruits, restricted salt intake, and physical activity should be maintained. No two drugs (ACEi and ARBs) that act separately on the renin-angiotensin system should be used in combination because of the risks of hyperkalemia, acute kidney injury, and hypotension ${ }^{6)}$. It is preferred to combine agents from different drug classes and complementary modes of action ${ }^{6}$.

\section{Treatment-resistant or refractory HTN}

When a therapeutic plan that includes lifestyle modifications and intake of three or more antihypertensive drugs (one diuretic) at maximally effective doses has failed to lower SBP and DBP sufficiently ${ }^{23,24)}$, HTN may be defined as resistant to treatment or refractory ${ }^{6,7)}$. This condition

Table 2. Non-pharmacologic and Pharmacologic Treatment of Pediatric Hypertension

\begin{tabular}{|c|c|c|}
\hline & 2017 AAP CPG & 2016 ESHG \\
\hline \multirow[t]{3}{*}{$\begin{array}{l}\text { Lifestyle } \\
\text { modifications }\end{array}$} & DASH-type diet & $\begin{array}{l}3 \text { months of exercise training } \rightarrow \text { lowering SBP 7-12 mmHg and DBP 2-7 } \\
\mathrm{mmHg}\end{array}$ \\
\hline & $\begin{array}{l}\text { Moderate to vigorous physical activity: at least } 3 \text { to } 5 \\
\text { days per week (30-60 min per session) }\end{array}$ & $\begin{array}{l}\text { More than two servings of fruits and vegetables/day } \rightarrow \text { lowering the risk of } \\
\text { HTN by } 35 \%\end{array}$ \\
\hline & Motivational interviewing, Stress reduction & $3 \mathrm{~g} /$ day reduction in salt intake $\rightarrow$ lowering SBP and DBP of $1.2 / 1.3 \mathrm{mmHg}$ \\
\hline \multirow[t]{2}{*}{$\begin{array}{l}\text { Pharmacologic } \\
\text { treatment }\end{array}$} & $\begin{array}{l}\text { Indications: lifestyle modifications failure, LVH on } \\
\text { echocardiography, symptomatic HTN, stage } 2 \text { HTN } \\
\text { without a clearly modifiable factor (obesity etc.) }\end{array}$ & $\begin{array}{l}\text { Indications: symptomatic, secondary, organ damage, diabetes, hypertensive } \\
\text { emergency and urgency }\end{array}$ \\
\hline & ACEi, ARBs, long-acting CCBs, thiazide diuretics & ACEi, ARBs, calcium antagonist, beta blockers, thiazide diuretics \\
\hline Remarks & $\begin{array}{l}\text { Target BP: SBP and DBP to <90th percentile and } \\
<130 / 80 \mathrm{mmHg} \text { in younger children }\end{array}$ & ACEi should not be used with ARBs \\
\hline
\end{tabular}

Abbreviations: AAP CPG, American Academy of Pediatrics Clinical Practice Guideline; ESHG, European Society of Hypertension Guideline; DASH, dietary approaches to stop hypertension; BP, blood pressure; LVH, left ventricular hypertrophy; HTN, hypertension; SBP, systolic blood pressure; DBP, diastolic blood pressure; ACEi, angiotensin-converting enzyme inhibitors; ARBs, angiotensin receptor blockers; CCBs, calcium channel blockers. 
requires precise investigation of the secondary causes of resistant HTN and prompt intervention. Primary glomerulopathies, renovascular disease, coarctation of the aorta, and neurological tumors are the most common causes of secondary HTN in children $<6$ years of age (Table 3 ). According to the clinical status, renal Doppler ultrasonography, magnetic resonance imaging, and computed tomography angiography may be helpful in the differential diagnosis. In addition, renin-aldosterone values and serum potassium levels provide important information to help rule out the genetic causes of HTN. Ambulatory BP monitoring may be performed to identify true resistant HTN and confirm the diagnosis ${ }^{7}$.

Treatment includes dietary sodium restriction, avoidance of substances and drugs known to elevate BP, the identification of previously undiagnosed secondary causes of HTN, the optimization of current therapy, and the addition of extended-release drugs at the highest dose as needed

${ }^{7,25)}$. As there are limited data related to treatment-resistant HTN in children, evaluation and management strategies similar to those effective in adults should be taken ${ }^{7)}$.

\section{Treatment of monogenic HTN}

Monogenic HTN syndromes refer to hypertensive disorders caused by a single gene mutation that follows Mendelian inheritance patterns ${ }^{26}$. According to the 2017 AAP CPG, monogenic forms of HTN are uncommon because of the lack of exact incidence data ${ }^{7}$. In the 2016 ESHG, the Working Group also stated that monogenic causes of HTN are rare but should be discovered during the pediatric age for successful treatment and avoidance of HTN-related morbidity and mortality in adulthood ${ }^{6}$.

Although genetic testing is a confirmative tool for diagnosis, monogenic causes of HTN may be suspected in low renin HTN, family history of early onset HTN, death from cerebral vascular accidents and heart failure, and refractory $\mathrm{HTN}^{6}$. Early recognition and proper management are crucial because specific antihypertensive agents should be targeted to defective tubular function. Based on the results of genetic testing, treatment may consist of thiazides, amiloride, triamterene, dexamethasone, spironolactone, or eplerenone ${ }^{6}$.

\section{Conclusions}

HTN in childhood and adolescence progresses to adulthood HTN, resulting in increased cardiovascular events such as heart disease and stroke. Therefore, efforts should be made to detect children who are at risk of HTN to prevent progression to sustained HTN and to avoid the development of hypertensive CVD. Nonpharmacological and pharmacological treatments should be used in the management of children and adolescents with HTN. Prospective reassessment and ongoing revision are needed to improve the recommendations made in both guidelines with regular updates based on new evidence as it is generated.

\section{Funding}

This research did not receive any specific grant from fun-

Table 3. Etiology of Secondary Hypertension

\begin{tabular}{|c|c|}
\hline 2017 AAP CPG & 2016 ESHG \\
\hline Renal parenchymal disease and renal structural abnormalities & Chronic kidney disease \\
\hline Renovascular disease & Renovascular HTN \\
\hline Cardiac, including aortic coarctation & Pheochromocytoma and paraganglioma \\
\hline $\begin{array}{l}\text { Endocrine HTN: catecholamine excess, mineralocorticoid excess, glucocorticoid } \\
\text { excess, hyperthyroidism, hyperparathyroidism etc. }\end{array}$ & Primary aldosteronism \\
\hline Environmental exposures: lead, cadmium, mercury, phthalates etc. & Cushing's syndrome \\
\hline Neurofibromatosis & Obstructive sleep apnea \\
\hline Pheochromocytoma & Coarctation of aorta \\
\hline Medication-related HTN & Drug-induced HTN \\
\hline \multirow[t]{2}{*}{ Monogenic HTN } & Monogenic causes of HTN \\
\hline & Hyperthyroidism and congenital adrenal hyperplasia \\
\hline
\end{tabular}

Abbreviations: AAP CPG, American Academy of Pediatrics Clinical Practice Guideline; ESHG, European Society of Hypertension Guideline; HTN, hypertension. 
ding agencies in the public, commercial, or not-for-profit sectors.

\section{Conflicts of interest}

\section{No potential conflict of interest relevant to this article was reported.}

\section{ORCID}

\section{Se Jin Park, https://orcid.org/0000-0002-7650-5393 Jae Il Shin, https://orcid.org/0000-0003-2326-1820}

\section{References}

1. National High Blood Pressure Education Program Working Group on High Blood Pressure in Children and Adolescents. The fourth report on the diagnosis, evaluation, and treatment of high blood pressure in children and adolescents. Pediatrics 2004;114:555-76.

2. Rademacher ER, Jacobs DR Jr, Moran A, Steinberger J, Prineas RJ, Sinaiko A. Relation of blood pressure and body mass index during childhood to cardiovascular risk factor levels in young adults. J Hypertens 2009;27:1766-74.

3. Falkner B, Lurbe E. Primary hypertension beginning in childhood and risk for future cardiovascular disease. J Pediatr 2021;238:1625.

4. Falkner B, Gidding S. Life-course implications of pediatric risk factors for cardiovascular disease. Can J Cardiol 2021;37:766-75.

5. Wühl E. Hypertension in childhood obesity. Acta Paediatr 2019; 108:37-43

6. Lurbe E, Agabiti-Rosei E, Cruickshank JK, Dominiczak A, Erdine S, Hirth A, et al. 2016 European Society of Hypertension guidelines for the management of high blood pressure in children and adolescents. J Hypertens 2016;34:1887-920.

7. Flynn JT, Kaelber DC, Baker-Smith CM, Blowey D, Carroll AE, Daniels SR, et al. Clinical practice guideline for screening and management of high blood pressure in children and adolescents. Pediatrics 2017;140:e20171904.

8. Tran AH, Urbina EM. Hypertension in children. Curr Opin Cardiol 2020;35:376-80.

9. Bonito PD, Licenziati MR, Baroni MG, Maffeis C, Morandi A, Manco $M$, et al. The American Academy of Pediatrics hypertension guidelines identify obese youth at high cardiovascular risk among individuals non-hypertensive by the European Society of Hypertension guidelines. Eur J Prev Cardiol 2020;27:8-15.
10. Blanchette E, Flynn JT. Implications of the 2017 AAP clinical practice guidelines for management of hypertension in children and adolescents: a review. Curr Hypertens Rep 2019;21:35.

11. Rosner B, Cook N, Portman R, Daniels S, Falkner B. Determination of blood pressure percentiles in normal-weight children: some methodological issues. Am J Epidemiol 2008;167:653-66.

12. Whelton PK, Carey RM, Aronow WS, Casey DE Jr, Collins KJ, Himmelfarb CD, et al. 2017 ACC/AHA/AAPA/ABC/ACPM/AGS/APhA/ ASH/ASPC/NMA/PCNA guideline for the prevention, detection, evaluation, and management of high blood pressure in adults: executive summary: a report of the American College of Cardiology/American Heart Association task force on clinical practice guidelines. Circulation 2018;138:e426-83.

13. Sharma AK, Metzger DL, Rodd CJ. Prevalence and severity of high blood pressure among children based on the 2017 American Academy of Pediatrics guidelines. JAMA Pediatr 2018;172:557-65.

14. Khoury M, Khoury PR, Dolan LM, Kimball TR, Urbina EM. Clinical implications of the revised AAP pediatric hypertension guidelines. Pediatrics 2018;142:e20180245.

15. Dong Y, Song Y, Zou Z, Ma J, Dong B, Prochaska JJ. Updates to pediatric hypertension guidelines: influence on classification of high blood pressure in children and adolescents. J Hypertens 2019:37:297-306.

16. Al Kibria GM, Swasey K, Sharmeen A, Day B. Estimated change in prevalence and trends of childhood blood pressure levels in the United States after application of the 2017 AAP guideline. Prev Chronic Dis 2019;16:E12.

17. ESCAPE Trial Group, Wühl E, Trivelli A, Picca S, Litwin M, PecoAntic A, et al. Strict blood-pressure control and progression of renal failure in children. N Engl J Med 2009;361:1639-50.

18. Raile K, Galler A, Hofer S, Herbst A, Dunstheimer D, Busch P, et al. Diabetic nephropathy in 27,805 children, adolescents, and adults with type 1 diabetes: effect of diabetes duration, A1C, hypertension, dyslipidemia, diabetes onset, and sex. Diabetes Care 2007; 30:2523-8

19. Lurbe E, Redon J, Kesani A, Pascual JM, Tacons J, Alvarez V, et al. Increase in nocturnal blood pressure and progression to microalbuminuria in type 1 diabetes. N Engl J Med 2002;347:797-805.

20. Ho M, Garnett SP, Baur L, Burrows T, Stewart L, Neve M, et al. Effectiveness of lifestyle interventions in child obesity: systematic review with meta-analysis. Pediatrics 2012;130:e1647-71.

21. Elliott WJ, Meyer PM. Incident diabetes in clinical trials of antihypertensive drugs: a network meta-analysis. Lancet 2007;369: 201-7.

22. Mancia G, Grassi G, Zanchetti A. New-onset diabetes and antihypertensive drugs. J Hypertens 2006;24:3-10.

23. Mancia G, Fagard R, Narkiewicz K, Redón J, Zanchetti A, Böhm M, et al. 2013 ESH/ESC guidelines for the management of arterial hypertension: the task force for the management of arterial hypertension of the European Society of Hypertension (ESH) and of the European Society of Cardiology (ESC). J Hypertens 2013;31:1281-357. 


\section{www.chikd.org}

24. Macumber I, Flynn JT. Does treatment-resistant hypertension exist in children? A review of the evidence. Pediatr Nephrol 2020; 35:969-76.

25. White WB, Turner JR, Sica DA, Bisognano JD, Calhoun DA, Townsend RR, et al. Detection, evaluation, and treatment of severe and
Park SJ and Shin Jl Guidelines for Pediatric Hypertension 77

resistant hypertension: proceedings from an American Society of Hypertension Interactive Forum held in Bethesda, MD, U.S.A., October 10th 2013. J Am Soc Hypertens 2014;8:743-57.

26. Ahn SY, Gupta C. Genetic programming of hypertension. Front Pediatr 2018;5:285. 